\title{
REVIEW
}

\section{Changes produced in the urothelium by traditional and newer therapeutic procedures for bladder cancer}

\author{
A Lopez-Beltran, R J Luque, R Mazzucchelli, M Scarpelli, R Montironi
}

J Clin Pathol 2002;55:641-647

A handful of traditional and newer therapeutic procedures, such as chemotherapy, immunotherapy, radiotherapy, photodynamic and laser treatment, and gene therapy, are used to treat epithelial malignancies of bladder origin. These treatment modalities, used either intravesically or systemically, produce morphological changes in the urothelial mucosa that can be mistaken for carcinoma. The pathologist must be able to separate toxic and drug related alterations from tumour related changes. The clinical history is usually invaluable in this assessment.

See end of article for authors' affiliations

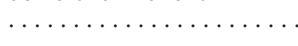

Correspondence to: Professor R Montironi, Institute of Pathological Anatomy and Histopathology, School of Medicine, University of Ancona, Azienda Ospedaliera Umberto $I^{\circ}$, 60020 Torrette, Ancona, Italy; r.montironi@ popcsi.unian.it

Accepted for publication 22 May 2002
$\mathrm{B}$ ladder cancer has proved to be a great challenge to pathologists and urologists. Bladder cancer is a paradigm of malignancy. Some cancers are of low malignancy potential, whereas others are highly aggressive, making early diagnosis and appropriate treatment crucial. In most cases, transurethral resection of the bladder (TURB) is the primary mode both of treatment and diagnosis. ${ }^{1}$ Persistent high grade tumours confined to the urothelial mucosa may require further treatment to prevent recurrence or possible progression. Further treatment is usually in the form of intravesical therapy or immunotherapy. Alternative therapeutic approaches, such as gene therapy, have been adopted in recent times. $^{23}$ Although superficial bladder cancer is managed conservatively, muscle invasive bladder cancer is usually treated with radical cystectomy or radical radiotherapy. ${ }^{4}$ Systemic chemotherapy has been added to surgical and radiotherapy in an attempt to improve cure rates.

\begin{abstract}
"There are few data on the morphological changes induced in the normal mucosa and the associated neoplasia in relation to the different therapeutic approaches"
\end{abstract}

A host of information is available on the morphological appearance of untreated bladder cancer, both in its pre-invasive and invasive phases. ${ }^{56}$ The literature dealing with the treatment of bladder cancer offers little information about the tissue and cellular changes related to the various types of treatment. Most studies document the efficacy of treatment on the basis of the endoscopic appearance of the bladder, not always confirmed by histology. There are few data on the morphological changes induced in the normal mucosa and the associated neoplasia in relation to the different therapeutic approaches. ${ }^{67}$
Here, we aim to review the morphological changes induced in the bladder by a series of traditional and innovative therapeutic procedures used to treat bladder cancer, including the alterations induced by cyclophosphamide, a systemic chemotherapeutic agent used to treat lesions other than bladder cancer. In particular, the following groups of topical and systemic therapeutic procedures together with the morphological changes induced by them are reviewed:

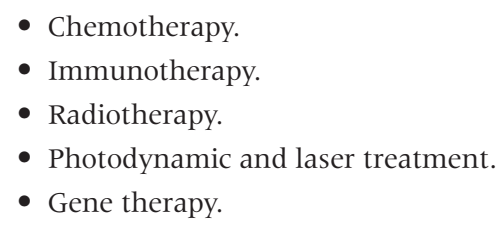

\section{CHEMOTHERAPY}

Several chemotherapeutic agents, used either intravesically or systemically, produce urothelial changes. Some of them can be mistaken for carcinoma.

\section{Intravesical chemotherapy}

The fundamental purpose of treatment with intravesical chemotherapy is threefold:

(1) eradication of existing disease,

(2) prevention of recurrence,

(3) prevention of tumour progression. ${ }^{8}$

Common indications for intravesical chemotherapy include multiple primary tumours, frequent tumour recurrence, stage Tl grade 3 tumours, post resection positive urine cytology, and carcinoma in situ (CIS). Several intravesical chemotherapeutic agents are used.

Triethylenethiophosphoramide (thiotepa) and mitomycin C

Thiotepa, an alkylating agent, is the oldest of the intravesical chemotherapeutic agents still actively used today. Its mechanism of action involves the formation of covalent bonds between DNA, RNA, nucleic acids, and protein. ${ }^{9}$ The result is the inhibition of nucleic acid synthesis. In addition to this effect, thiotepa reduces cell adherence, with a direct cytotoxic effect. ${ }^{10}$

Mitomycin C, an antitumour antibiotic, can induce interstrand and intrastrand crosslinks in many types of DNA, depending on the base composition of the DNA. It has been shown to

Abbreviations: BCG, Bacillus Calmette-Guérin; CIS, carcinoma in situ; IFN, interferon; IL, interleukin; TURB transurethral resection of the bladder 
Table 1 Cytological features associated with intravesical chemotherapy and low grade urothelial tumours

\begin{tabular}{lll}
\hline Feature & Thiotepa, mitomycin C & Low grade urothelial tumour \\
\hline Cellularity & Early: high & Usually high \\
Lell size & Enlarged & Normal to minimal enlargement \\
Nuclear/cytoplasmic ratio & Normal & Increased \\
Staining & Hyperchromatic & Hyperchromatic \\
Nuclear borders & Irregular & Irregular \\
Chromatin & Fine, regular & Fine, regular \\
Nucleoli & Variable & Variable \\
Multinucleated cells and vacuolated cytoplasm & Common & Rare \\
Architecture & Loose, dyscohesive & Papillary and loose clusters \\
DNA ploidy & Diploid & Usually diploid \\
\hline & &
\end{tabular}

degrade DNA and inhibit DNA synthesis, thus making it effective during the late $\mathrm{Gl}$ and $\mathrm{S}$ phases of the cell cycle. ${ }^{.1}$

\section{"A pronounced necroinflammatory process, with the features of so called chemical cystitis, follows the topical administration of mitomycin C"}

Thiotepa and mitomycin C produce identical histological and cytological alterations in the normal urothelium. ${ }^{12}{ }^{13}$ In particular, these agents induce cell exfoliation and mucosal denudation, and produce atypical changes in the superficial umbrella cells. ${ }^{12}$ Such cells become large, vacuolated, and often multinucleated with small nucleoli. ${ }^{13}$ These atypical looking cells can persist in the cytological specimens for several weeks after the discontinuation of treatment. ${ }^{7}$ Table 1 summarises the cytological criteria that are useful to distinguish thiotepa and mitomycin $\mathrm{C}$ induced changes from low grade urothelial tumours. These cell alterations are not specific and may also be caused by chronic irritation such as inflammation, catheterisation, and instillation of saline solutions (fig 1A,B). ${ }^{72-14}$

A pronounced necroinflammatory process, with the features of so called chemical cystitis, follows the topical administration of mitomycin C. There is often a histiocytic response that extends deep into the bladder wall, the macrophages being either isolated or in clusters. Mitomycin C may also initiate eosinophilic cystitis. Significant fibrosis with scarring and bladder wall calcification have been documented in isolated cases after long term topical treatment (table 2). ${ }^{15}$

Thiotepa and mitomycin C suppress tumour growth and progression, but they do not eradicate cancer. Apparently, they act as surface abrasives to destroy the tips of papillary fronds, resulting in stubby papillae lined by neoplastic cells. Urothelial denudation makes recurrences difficult to detect cystoscopically and to document histologically, but urothelial dysplasia and carcinoma in situ have been found in von Brunn's nests. ${ }^{6}$

\section{Other topical agents}

Doxorubicin (Adriamycin), epirubicin, ethoglucid (epodyl), cisplatin, and mitoxantrone are known to cause alterations in the bladder mucosa. ${ }^{16}{ }^{17}$ The frequency varies from agent to agent. For instance, there is a $21 \%$ and $25 \%$ incidence of epirubicin and doxorubicin induced cystitis, respectively. A frequency of cystitis ranging from 3\% to $56 \%$ has been seen with ethoglucid. The full morphological description of the changes in the normal bladder mucosa and in the lesions being treated is not available.

\section{Systemic chemotherapy}

Several agents are given systemically to treat neoplastic and non-neoplastic disorders. Among these agents, cyclophosphamide is known to have severe effects on the bladder mucosa.

\section{Cyclophosphamide}

Cyclophosphamide is an alkylating agent used either alone or in combination with other compounds to treat epithelial malignancies, in addition to diseases such as systemic lupus erythematosus, rheumatoid arthritis, nephrotic syndrome, organ transplantation, and lymphoproliferative disorders. ${ }^{18}$ Active metabolites, namely acrolein and phosphoramide mustard, are concentrated in the urine, where they can be in contact with the urothelium for prolonged periods. ${ }^{19}$ The drug is toxic to the urinary bladder mucosa and increases the risk of urinary bladder cancer (table 3 ; fig lC). ${ }^{2021}$

Cyclophosphamide causes the arrest of cell division and produces large, binucleated and multinucleated cells, often with large bizarre nuclei resembling those seen after radiotherapy (see below). There is pronounced but variable cellular and nuclear enlargement. Nuclei are often eccentric, slightly irregular in outline, and usually very hyperchromatic. Chromatin may be coarse but is usually evenly distributed. Nuclear piknosis is a common late effect that results in the loss of chromatin texture. Nucleoli are single or double and are occasionally large and distorted with irregular and sharp edges. Such cytological abnormalities of the urothelial cells may be easily mistaken for malignancy. ${ }^{22}$

"The risk of bladder cancer associated with cyclophosphamide is apparently increased in patients with a history of cystitis"

Haemorrhagic cystitis can be caused by systemic cyclophosphamide treatment ${ }^{19}$ and it appears to be dose independent. ${ }^{23}$ The histological changes include vascular ectasia with severe oedema and haemorrhage of the lamina propria, usually associated with necrosis of the epithelial lining and mucosal ulceration. Fibrosis of the lamina propria and the muscularis propria is present in $25 \%$ of cases examined at necropsy. ${ }^{24-26}$ Bladder wall calcification has been seen in occasional cases. ${ }^{25}$ Haemorrhagic cystitis occurs also in patients treated with busulfan. ${ }^{16}$

Systemic cyclophosphamide treatment may induce reactivation of polyomavirus infection. Early in the reactivation process cells shedding from the bladder may mimic dysplasia or urothelial carcinoma. ${ }^{27}$ DNA aneuploidy or a hyperdiploid DNA content may be encountered as a false positive indicator of transitional cell carcinoma in patients with reactivated polyomavirus associated with urothelial atypia and no evidence of transitional cell carcinoma. ${ }^{27}$

The evidence that cyclophosphamide increases the risk of bladder cancer is primarily based on a summary of case reports, but there is some evidence that the risk increases with the cumulative total dose of cyclophosphamide. ${ }^{28}$ Bladder cancer occurs, most commonly, several years after the treatment of lymphoproliferative or myeloproliferative disorders, particularly multiple myeloma and Hodgkin's disease, 


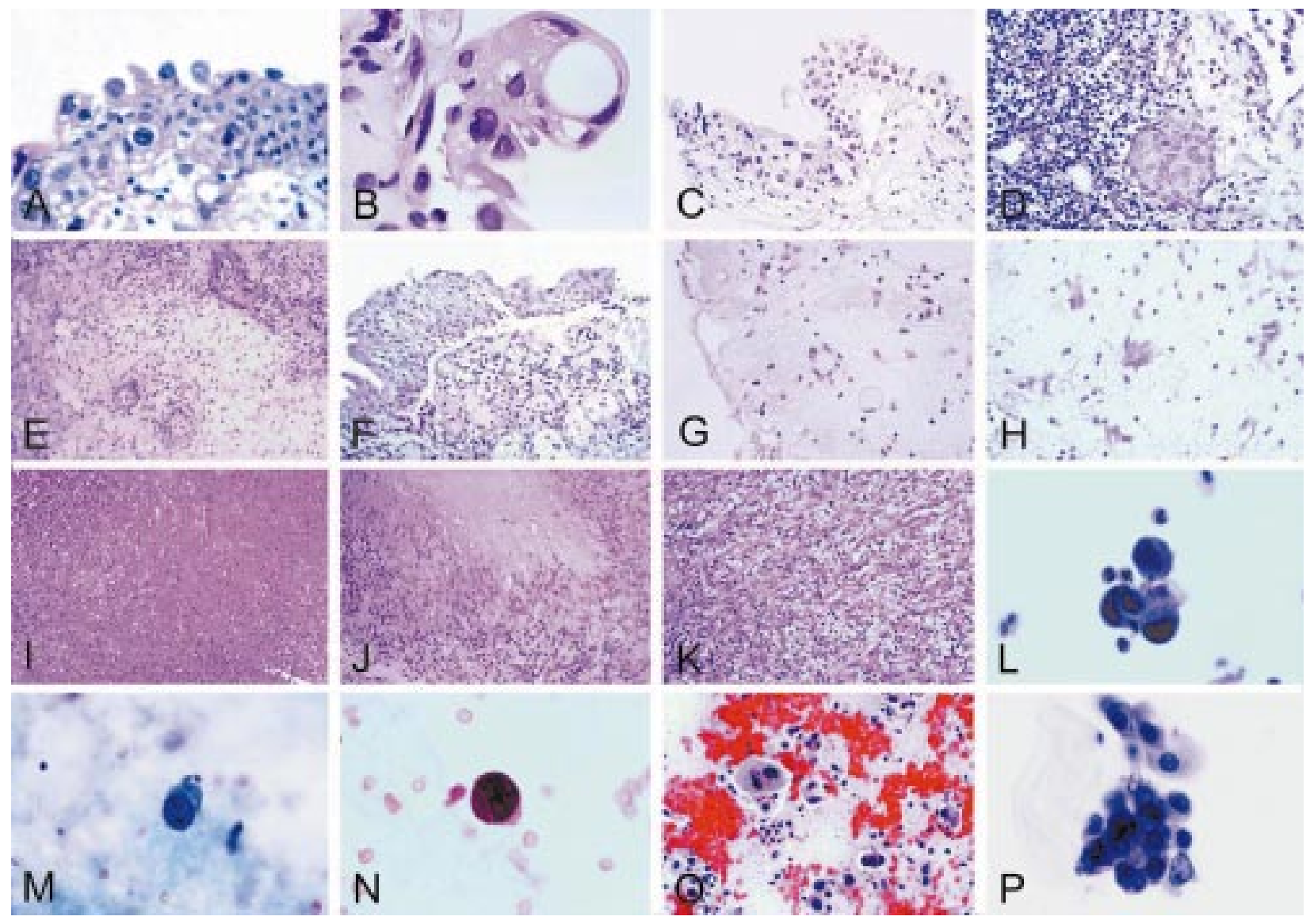

Figure 1 (A) Early histological changes in the urothelium after mitomycin $C$ treatment. The superficial umbrella cells are large, vacuolated, and binucleated (original magnification, $\times 400$; haematoxylin and eosin stained). (B) The effect of treatment with thiotepa. The changes are more pronounced than in (A) (see also text) (original magnification, $\times 400$; haematoxylin and eosin stained). (C) The effect of treatment with cyclophosphamide. Large cells with large bizarre nuclei are easily identifiable (original magnification, $\times 250$; haematoxylin and eosin stained). (D) The effect of treatment with BCG. Residual urothelial carcinoma. Denudation of the urothelium is present (upper right corner) (original magnification, $\times 400$; haematoxylin and eosin stained). (E) The effect of treatment with interferon $\alpha$. Oedema of the lamina propria, or subepithelial connective tissue, and perivascular collections of inflammatory cells are present (original magnification, $\times 400$; haematoxylin and eosin stained). (F) Acute radiation cystitis. Partial detachment of the urothelium from the lamina propria where a mild inflammatory infiltrate is recognisable (original magnification, $\times 250$; haematoxylin and eosin stained). (G) Acute radiation cystitis. Oedema of the lamina propria with atypical looking endothelial and stromal cells (original magnification, $\times 250$; haematoxylin and eosin stained). (H) Atypical looking stromal cells ("radiation fibroblasts") similar to those seen in giant cell cystitis (original magnification, $\times 400$; haematoxylin and eosin stained). (I) Coagulation necrosis after laser treatment (original magnification, $\times 100$; haematoxylin and eosin stained). (J) Postsurgical necrobiotic granuloma (original magnification, $\times 250$; haematoxylin and eosin stained). (K) Postoperative spindle cell nodule (original magnification, $\times 250$; haematoxylin and eosin stained). (L) Urinary cytology after topic mitomycin C treatment. Cluster of atypical looking cells with degenerative features (original magnification, $\times 400$; Papanicolaou stain). (M) Urinary cytology after systemic cyclophosphamide treatment. Atypical looking cell with enlarged, eccentrically located, and extremely hyperchromatic nucleus (original magnification, $\times 400$; Papanicolaou stain). (N) Urinary cytology after systemic cyclophosphamide treatment. Atypical looking cell in a patient with reactivation of polyomavirus infection (original magnification, $\times 400$; Papanicolaou stain). (O) Urinary bladder cytology after external beam radiation. Degenerated urothelial cells and extensive background debris with histiocytes (original magnification, $\times 250$; Papanicolaou stain). (P) Atypical epithelial cells in the urinary cytology after BCG treatment in a patient with urothelial carcinoma in situ (original magnification, $\times 400$; Papanicolaou stain).

Table 2 Pathological alterations associated with intravesical chemotherapy (thiotepa and mitomycin C)

- $\quad$ "Atypical" changes in the superficial umbrella cells
- Large cells with nuclear enlargement, multinucleation, and
small nucleoli on cytological examination (see also table 8)
Eosinophilic cystitis (rare)
- Haemorrhagic cystitis (rare)
Encrusted cystitis (rare)

and in patients receiving cyclophosphamide after organ transplantation. $^{18} 212930$ The risk of bladder cancer associated with cyclophosphamide is apparently increased in patients with a history of cystitis. Urothelial carcinoma is the most
Table 3 Pathological alterations associated with systemic cyclophosphamide treatment

- Large, binucleated and multinucleated urothelial cells often with large bizarre nuclei resembling changes of radiation injury

- Haemorrhagic cystitis

- Reactivation of polyomavirus infection

- Encrusted cystitis (rare)

- Bladder cancer following cyclophosphamide treatment (uncommon)

common form of cancer, although squamous cell carcinoma, adenocarcinoma, undifferentiated carcinoma, and even sarcomas have been observed. Sarcomatoid carcinomas (carcinosarcoma) have also been reported in a few patients after prolonged administration. ${ }^{20}{ }^{21}$ 
Table 4 Pathological alterations associated with intravesical immunotherapy (BCG, interferon $\alpha$ )

- Denudation and ulceration of urothelium
- $\quad$ Rean-caseating granulomas
- wegith histionerated urothelial cells and extensive background debris
cytological examination
- $\quad$ Mild perivascularinucleated giant cells on
plasma cells, and dendritic cells (interferon $\alpha$ )
- Persistence of carcinoma in situ (in von Brunn's nests)

In patients with muscle invasive bladder cancer, systemic (neoadjuvant) chemotherapy, in which cyclophosphamide may be given in combination with other agents, has been added to locoregional treatment in an attempt to downstage the primary tumour and reduce micrometastases and, in some instances, as a radiosensitiser. ${ }^{31}$ The morphological changes are basically characterised by tumour cell necrosis. ${ }^{32}$ A similar effect can be seen following peri-operative chemotherapy.

\section{Immunotherapy Intravesical BCG}

Ideally, intravesical treatment should eradicate residual disease and prevent tumour recurrence, thus ultimately averting the serious consequences of muscle invasion and metastasis. The immunotherapeutic agent Bacillus Calmette-Guérin (BCG) offers high rates of early and durable complete response. However, although several studies have demonstrated a decrease in disease progression, there are no long term studies that provide conclusive evidence of a survival advantage to BCG.

BCG is a pleiotropic immune stimulator oriented toward cellular immunity. In particular, BCG has been shown to activate macrophages, natural killer cells, $B$ cells, and various $T$ cells (CD4+, CD8+, and $\gamma \delta \mathrm{T}$ cells) in vitro and in vivo. The analysis of cytokine production from human urine during BCG treatment has shown that BCG can stimulate the expression of interleukins (IL-1, IL-2, IL-4, IL-6, IL-8, IL-10, and IL-12), tumour necrosis factor $\alpha$, granulocyte-macrophage colony stimulating factor, the antiangiogenic chemokine IP-10, and interferon $\gamma($ IFN- $\gamma)$. Of these, IFN- $\gamma$ appears to be a crucial mediator of the anti-mycobacterial infection response. Although the exact mechanism of BCG action in bladder cancer remains incompletely understood, BCG antitumour efficacy appears to depend on a cell mediated $\mathrm{T}$ helper cell immune response. ${ }^{233}$

The pathological changes associated with BCG treatment are similar to those seen in tuberculous cystitis. This includes acute and chronic inflammation surrounding non-caseating granulomas. BCG may also produce a pattern of reactive epithelial atypia in association with denudation and ulceration of the urothelium (table 4; fig lD). ${ }^{34-36}$

\section{Immunotherapeutic agents other than BCG}

Several immunotherapeutic agents other than BCG have been investigated for the prophylaxis of superficial bladder cancer, including recombinant IFN- $\alpha .^{23}$ IFNs are known to have antiviral and direct antiproliferative activity, and to inhibit angiogenesis, regulate differentiation, activate immune effector cells, induce cytokine production, and enhance tumour associated antigen expression. ${ }^{2}$ The precise role of recombinant IFN- $\alpha$ in the treatment of superficial bladder cancer is still under investigation. ${ }^{33}$

Bladder cancer cells express large numbers of the IFN- $\alpha$ receptor, and greater receptor densities are found in high grade lesions. The indirect antitumour effects of IFNs are
Table 5 Radiation related pathological alterations

- Ulceration of urothelium

- Urothelial cell enlargement, mutinucleation, and cytoplasmic vacuolisation, but nuclear to cytoplasmic ratios remain low

- Acute and/or chronic inflammation of the lamina propria

- Nodules of squamoid epithelium (reactive)

- Giant cell cystitis

- Bladder wall fibrosis (late stage)

probably mediated via the stimulation of a cellular immune response. Intravesical recombinant IFN- $\alpha$ increases the cytotoxic activity of $\mathrm{T}$ cells and natural killer cells by increasing the infiltration of these cells into the bladder wall, and this improved immune cell activity persists for three to six months. This increases the susceptibility of urothelial carcinoma cells to attack from cytotoxic $T$ cells and directly inhibits the proliferation of tumour cells. ${ }^{2}$

The pathological changes associated with IFN based treatment are not specific and are characterised by oedema of the lamina propria and perivascular collections of inflammatory cells, mainly lymphocytes, neutrophils, and eosinophils.

Intravesical vaccinia virus is currently under study as immunotherapy for bladder cancer. ${ }^{36-39}$ The limited number of tested cases has shown a significant mucosal and submucosal inflammatory infiltration, characterised by lymphocytes, eosinophils, plasma cells, and dendritic cells (table 4; fig lE). The tumour cells show some nuclear features that suggest a viral effect.

\section{Radiotherapy}

Approximately $20-25 \%$ of patients present with muscle invasive bladder cancer, which is life threatening, and require radical treatment. Definitive radiotherapy has been used for muscle invasive bladder cancer since the early 1900s and there is evidence that patients can achieve durable local control and maintain a functional bladder. However, the standard approach to the management of bladder cancer not suitable for conservative measures is radical cystectomy. In the past few decades, radical radiotherapy has been used in patients who either refused or were not suitable for radical cystectomy. Therefore, there is a limited amount of information on the precise role that radiotherapy plays in the management of bladder cancer.

External beam radiotherapy is rarely appropriate for the treatment of superficial bladder cancer because it can cause considerable local morbidity while displaying limited efficacy. CIS is particularly resistant and low grade disease responds less well than higher grade disease. Some benefit may be derived for patients with stage Tl grade 3 tumours, especially if combined with aggressive TURB and chemotherapy. A high degree of local morbidity is seen in the bladder as a result of radiotherapy for other pelvic diseases. The mechanism by which these effects are accomplished is poorly understood, and it is possible that $x$ rays may eradicate tumours by severely damaging their blood supply. ${ }^{40-42}$

\section{"A variety of radiotherapy induced abnormalities may} be seen in the bladder mucosa"

A variety of abnormalities may be seen in the bladder mucosa. These include acute and chronic radiation cystitis, with mucosal ulceration and late bladder contracture. ${ }^{72-46}$ In particular, radiotherapy results in urothelial cell enlargement, multinucleation, and vacuolisation, although nuclear to cytoplasmic ratios remain low. Enlarged nuclei may have large nucleoli, but degenerative nuclear features are usually present. A reactive, tumour-like epithelial proliferation associated with 
Table 6 Pathological alterations associated with photodynamic and laser treatment

- Coagulation necrosis, sometimes with haemorrhagic necrosis, clearly demarcated from non-neoplastic tissue

- Intravascular coagulation

- Moderate to severe oedema of the normal urothelial mucosa. Necrosis is rare

- Spindle cell artifact of urothelial cells

- Dystrophic calcification
Table 7 Pathological changes associated with gene therapy

- Various degrees of necrosis in cancer foci with loss of chromatin detail and nucleoli in the earlier phases following treatment

- In the late phases, the nuclei shrink, become pyknotic, and acquire a spindled morphology

- Normal urothelial mucosa is rarely affected by necrosis

- Intense chronic inflammatory infiltrate composed predominantly of $B$ cells in the lamina propria haemorrhage, fibrin deposits, fibroid vascular changes, and multinucleated stromal cells is seen in chronic cases. This late phase of radiation cystitis usually occurs months or years after ionising radiation. Nodules of squamoid epithelium push into the lamina propria without evidence of true infiltrative growth. The adjacent tissue is haemorrhagic with deposits of fibrin and, deeper within the stroma, mesenchymal cells are often large and multinucleated (for example, giant cell cystitis). Extensive scarring of the bladder wall is common (table 5; fig $\mathrm{lF}, \mathrm{G}, \mathrm{H})$.

An important long term effect of radiotherapy is de novo radiation induced bladder cancer. In general, it is a urothelial carcinoma; occasionally it is a squamous cell neoplasm. Rare examples of sarcomatoid carcinoma (or carcinosarcoma) and sarcoma of the urinary bladder have been reported. ${ }^{20} 4447$

\section{Photodynamic and laser treatment \\ Photodynamic treatment}

Photodynamic treatment using haematoporphyrin derivatives is a form of treatment applied in bladder cancer. It can achieve a high initial complete response rate, especially against CIS, but generalised cutaneous photosensitivity remains limiting. ${ }^{48}{ }^{49}$ Moreover, severe local irritative symptoms persisting for months are not uncommon, in addition to occasional bladder contractures.

It is based on the systemic or local administration of photosensitisers. These substances accumulate in tumour tissue but not, or to some extent only, in normal tissue. ${ }^{50}$ When the photosensitiser is activated by light, it produces tumour necrosis, preserving normal structures. The response is noted one or two days after the treatment is applied..$^{50}$ On histology, it is characterised by coagulation necrosis, sometimes with haemorrhagic necrosis clearly demarcated from the non-neoplastic tissue (table 6; fig 1I). Adjacent non-neoplastic tissues may show morphological changes ranging from moderate to severe oedema, but necrosis is rare. ${ }^{51}{ }^{52}$ Other findings include spindle cell artifact of urothelial cells and dystrophic calcification. ${ }^{53-55}$

The photosensitiser accumulates also in the stroma and in the vessel wall, suggesting tumour ischaemia as a possible mechanism of action. In fact, early morphological changes show intravascular coagulation and adjacent tumour cell necrosis.

\section{Laser treatment}

Laser treatment has been used to ablate bladder tumours. Lasers are usually reserved for patients with recurrent low grade tumours, because tissue is not usually available for histological evaluation. ${ }^{56}$ It is believed that the lack of biopsy tissue in such circumstances does not compromise patient care because these lesions are usually low grade Ta lesions. ${ }^{57} 58$ The neodymium:YAG laser has been most commonly used. Flexible fibres can usually be inserted through standard cystoscopes, or through cystoscopic equipment modified for use with laser fibres..$^{59-61}$

One advantage of the laser is that it allows for transmural coagulative necrosis without perforation and extravasation (Ross JS. Intravesicle chemotherapy associated atypia in urinary bladder surgical and cytopathology. Presented at the United States and Canadian Academy of Pathology meeting on genitourinary pathology, Washington DC, 1996). The boundary between the necrotic tissue and the surrounding tissue is sharp. The endothelial cells in the tissue adjacent to cancer may acquire an atypical looking appearance. The pathologists should avoid considering these cells as residual cancer. ${ }^{6263}$

\section{Gene therapy}

The discovery that many cancers develop in concert with the loss of function of specific genes, dubbed "tumour suppression genes", suggests that the replacement of such genes should be therapeutically useful. Studies of bladder cancer have yielded several candidate genes for therapeutic replacement. ${ }^{64}$ Among these are the cell cycle related genes Rb, p53, p21/wafl, and pl6. ${ }^{65-68}$

Tumour suppressor gene therapy is well suited for intravesical administration. Gene correcting and tumour vaccination studies have been shown to be effective in animals, in particular by increasing the sensitivity of bladder cancer cells to chemotherapeutic agents. ${ }^{69} 70$ These findings suggest that the combined regimen of gene replacement and chemotherapy may become an efficient and powerful tool for the treatment of bladder cancer.

Very few morphological studies of cytopathological effects of gene therapy have been published. ${ }^{71-74}$ Various degrees of necrosis, more commonly seen in high grade lesions, are present in cancer foci. Nuclear changes include the loss of chromatin detail and nucleoli in the earlier stages. In the late stages, the nuclei shrink, become pyknotic, and acquire a spindled morphology, in contrast to the normal round/ovoid shape. The resulting nucleus, found in dead cells, is dark, dense, pyknotic, and comma shaped with no nuclear detail. Hyperchromatic bizarre nuclei are occasionally seen.

\section{"The combined regimen of gene replacement and chemotherapy may become an efficient and powerful tool for the treatment of bladder cancer"}

The normal urothelial mucosa is rarely affected by necrosis, but contains an intense chronic inflammatory infiltrate composed predominantly of B cells. Some lymphocytic infiltration is present at the tumour-normal bladder interface or inside the tumour itself. Macrophages are abundant within tumour

Table 8 Surgery related pathological lesions

- Non-specific granulomatous reaction

- Postsurgical necrobiotic granuloma

- Xanthogranuloma (rare)

- Postoperative spindle cell nodule

- Suture granuloma

- Development of malignancies in bladder augmentations and intestinal conduits 


\section{Take home messages}

- The modalities used for the treatment of epithelial bladder cancer may produce morphological changes in the urothelial mucosa that could be mistaken for carcinoma so that the pathologist must be able to separate toxic and drug related alterations from tumour related changes

- Intravesicular chemotherapy with thiotepa and mitomycin C induces cell exfoliation and mucosal denudation, and produces atypical changes in the superficial umbrella cells, which can mimic the changes seen with low grade urothelial tumours

- Systemic chemotherapy with cyclophosphamide can also cause cytological changes that can be mistaken for malignancy. It can also cause haemorrhagic cystitis and the reactivation of polyomavirus infection, the effects of which can mimic carcinoma

- Immunotherapy with BCG can induce pathological changes similar to those seen in tuberculous cystitis, including inflammation surrounding non-caseating granulomas, and treatment with interferon also produces inflammatory changes

- Radiotherapy can induce acute and chronic radiation cystitis (including giant cell cystitis), with mucosal ulceration and late bladder contracture

- Little is known about the changes induced by gene therapy, although necrosis of tumour tissue and inflammatory changes in the normal mucosa have been documented

- The changes induced by surgery do not usually pose a diagnostic problem

- Thus, pathologists must be aware that, following these types of treatment, the clinical usefulness of urinary cytology is reduced

foci, mostly in areas of necrosis. Injection sites with haemorrhagic foci and a foreign body-type giant cell reaction are identifiable occasionally (table 7).

Data on the morphological changes resulting from methods of gene therapy other than tumour suppressor gene therapy (for example, pro-drug activation, immunomodulatory, and anti-angiogenesis) are not available.

\section{Surgery}

The bladder may show a variety of surgery related changes. These can be divided into three groups: pathological changes associated with transurethral resection of the bladder, suture granuloma and related lesions, and morphological changes associated with bladder augmentations and intestinal conduits (table 8; fig $1 \mathrm{~J}, \mathrm{~K}$ ). ${ }^{1375-86}$ Details were reported in a recent review. ${ }^{7}$ Usually these changes do not represent a diagnostic problem.

\section{CONCLUSIONS}

Topical and systemic therapeutic agents and treatment modalities, such as thiotepa and mitomycin C, cyclophosphamide, BCG, radiotherapy, photodynamic and laser treatment, and gene therapy, produce a host of changes and alterations in the bladder, some of them mimicking cancer. Pathologists must be aware that, following these types of treatment, the clinical usefulness of urinary cytology is reduced (fig $1 \mathrm{~L}-\mathrm{P}$ ).

\section{ACKNOWLEDGEMENTS}

This work has been supported by grants from the University of Ancona (RM, MS) and the Italian Ministry of University and Scientific Research (RM), and by a grant from the "Fondo de Investigacion Sanitaria, Madrid, Spain" (grant number 00/0898). The content of this paper is solely the responsibility of the authors and does not necessarily represent the official views of the University of Ancona and the University of Cordoba.

\section{Authors' affiliations}

A Lopez-Beltran, Department of Pathology, Reina Sofia University Hospital and Faculty of Medicine, 14004 Cordoba, Spain

R J Luque, Department of Pathology, Hospital Princesa de España, 23071 Jaen, Spain

R Mazzucchelli, M Scarpelli, R Montironi, Institute of Pathological Anatomy and Histopathology, Ancona University School of Medicine, 60020 Torrette, Ancona, Italy

\section{REFERENCES}

1 Eble JN, Banks ER. Postsurgical necrobiotic granulomas of the urinary bladder. Urology 1990;35:454-7

2 Belldegrun AS, Franklin JR, O'Donnell MA, et al. Superficial bladder cancer: the role of interferon- $\alpha$. J Urol 1998:159:1793-801.

3 Akasaka S, Suzuki S, Shimizu H, et al. Suicide gene therapy for chemically induced rat bladder tumor entailing instillation of adenoviral vectors. Jpn J Cancer Res 2001;92:568-75.

4 Antonakopoulous GN, Hicks RM, Berry RJ. The subcellular basis of damage to the urinary bladder induced by irradiation. J Pathol 1984;143:103-16

5 Bostwick DG, Mikuz G. Urothelial papillary (exophytic) neoplasms. Virchows Arch [In press.]

6 Lopez-Beltran A, Cheng L, Andersson L, et al. Preneoplastic non-papillary lesions and conditions of the urinary bladder: an update based on the Ancona International Consultation. Virchows Arch 2002;440:3-11.

7 Lopez-Beltran A. Bladder treatment: immunotherapy and chemotherapy. Urol Clin North Am 1999:26:535-554.

8 Badalament RA, Farah RN. Treatment of superficial bladder cancer with intravesical chemotherapy. Semin Surg Oncol 1997;13:335-41.

9 Wities JA, Oosterhof GON, Debruyne FMJ. In: Vogelzang NJ, Scardino PT, Shipley WU, et al, eds. Comprehensive textbook of genitourinary oncology, Philadelphia: Williams and Wilkins, 1996:416-27.

10 Weaver D, Khare N, Haigh J, et al. The effect of chemotherapeutic agents on the ultrastructure of transitional cell carcinoma in tissue culture. Invest Urol (Berl) 1980;17:288-92

11 Bird VG, Soloway MS, Malmström P. Intravesical chemotherapy in the treatment of superficial bladder cancer. In: Droller M, ed. Bladder cancer, current diagnosis and treatment. Totowa, New Jersey: Humana Press 2001:183-223.

12 Murphy WM, Soloway MS, Finebaum PJ. Pathologic changes associated with topical chemotherapy for superficial bladder cancer. J Urol 1980;126:461-4.

13 Murphy WM, Soloway MS, Lin CJ. Morphological effects of thio-TEPA on mammalian urothelium: changes in abnormal cells. Acta Cytol 1978;22:550-4

14 Choe JM, Kirkemo AK, Sirls LT. Intravesical thiotepa-induced eosinophilic cystitis. Urology 1995:46:729-31.

15 Drago PC, Badalament RA, Lucas $V$, et al. Bladder wall calcification after intravesical mitomycin $C$ treatment of superficial bladder cancer. J Urol 1989;142:1071-2.

16 Pode D, Perlberg S, Steiner D. Busulfan-induce hemorrhagic cystitis. J Urol 1983:130:347-8.

17 Scharf J, Nahir M, Eidelman S, et al. Carcinoma of the bladder with azathioprine therapy. JAMA 1977;237:152-5.

18 Lawrence HJ, Simone J, Aur RJA. Cyclophosphamide-induced hemorrhagic cystitis in children with leukemia. Cancer 1975;36:1572-6.

9 Stillwell TJ, Benson RC. Cyclophosphamide induced hemorrhagic cystitis. A review of 100 patients. Cancer 1988;61:451-7.

20 Lopez-Beltran A, Pacelli A, Rothemberg HJ, et al. Carcinosarcoma and sarcomatoid carcinoma of the bladder: clinicopathological study of 41 cases. J Urol 1998;159:1497-503.

21 Siddiqui A, Melamed MR, Abbi R, et al. Mucinous (colloid) carcinoma of urinary bladder following long-term cyclophosphamide therapy for Waldenström macroglobulinemia. Am J Surg Pathol 1996;20:500-4.

22 Forni AM, Koss LG, Geller W. Cytological study of the effect of cyclophosphamide on the epithelium of the urinary bladder in man. Cancer 1964:17:1348-55.

23 Goldman RL, Warner NE. Hemorrhagic cystitis and cytomegalic inclusion in the bladder associated with cyclophosphamide therapy. Cancer 1970;25:7-11.

24 Berkson BM, Lome LG, Shapiro I. Severe cystitis induced by cyclophosphamide. Role of surgical management. JAMA 1973;225:605-6.

25 Francis RS, Schackelford GD. Cyclophosphamide cystitis with bladder wall calcification. J Can Assoc Radiol 1974;25:324-6.

26 Johnson WW, Meadows DC. Urinary-bladder fibrosis and telangiectasia associated with long-term cyclophosphamide therapy. $N$ Engl J Med 1971;284:290-4

27 Woicik EM, Miller MC, Wright BC, et al. Comparative analysis of DNA content in polyomavirus-infected urothelial cells, urothelial dysplasia and high grade transitional cell carcinoma. Anal Quant Cytol Histol 1997; 19:430-6.

28 Wall RL, Clausen KP. Carcinoma of the urinary bladder in patients receiving cyclophosphamide. N Engl J Med 1975;293:271-3.

29 Alexandre J, Levy V, Hunault $M$, et al. Bladder neoplasms and cyclophosphamide. Apropos of 3 cases and review of the literature. Bull Cancer 1996;83:945-50. 
30 Rowland RG, Eble JN. Bladder leiomyosarcoma and pelvic fibroblastic tumor following cyclophosphamide therapy. J Urol 1983;130:344-6.

31 Raghavan D. Pre-emptive (neo-adjuvant) intravenous chemotherapy for invasive bladder cancer. Br J Urol 1988;61:1-8.

32 Moulder SL, Roth BJ. Systemic chemotherapy for urothelial transitional cell carcinoma: an overview of toxicity. Semin Urol Oncol 2001;19:194-201.

33 Stavropoulos NE, lochim E, Pavlidis N, et al. Local immune response after intravesical interferon gamma in superficial bladder cancer. $\mathrm{Br} J$ Urol 1998:81:875-9.

34 Belmatoug N, Levy-Djebbour S, Appelboom T, et al. Polyarthritis in 4 patients treated with intravesical BCG-therapy for carcinoma of the bladder. Rev Rhum Engl Ed 1993;60:162-6.

35 Bassi P, Milani C, Meneghini A, et al. Clinical value of pathologic changes after intravesical BCG therapy of superficial bladder cancer. Urology 1992;40:175-9.

36 Betz SA, See WA, Cohen MB. Granulomatous inflammation in bladder wash specimens after intravesical bacillus Calmette-Guerin therapy for transitional cell carcinoma of the bladder. Am J Clin Pathol 1993:99:244-8.

37 Gomella LG, Mastrangelo M, McCue PA, et al. Phase I study of intravesical vaccinia virus as a vector for gene therapy of bladder cancer. J Urol 2001;166:1291-5

38 Kuromatsu I, Matsuo K, Takamura S, et al. Induction of effective antitumor immune responses in a mouse bladder fumor model by using DNA of an alpha antigen from mycobacteria. Cancer Gene Ther 2001;8:483-90

39 Loskog A, Bjorkland A, Brown MP, et al. Potent antitumor effects of CD154 transduced tumor cells in experimental bladder cancer. J Urol 2001;166:1093-7.

40 Hietala SO, Winblad B, Hassler O. Vascular and morphological changes in the urinary bladder wall after irradiation. Int Urol Nephrol 1975;7:119-29.

41 Marks LB, Carroll PR, Dugan TC, et al. The response of the urinary bladder, urethra, and ureter to radiation and chemotherapy. Int J Radiat Oncol Biol Phys 1995;31:1257-80.

42 Mothersill C, O'Malley K, Harney $\mathrm{H}$, et al. Further investigation of the response of human uroepithelium to low doses of cobalt-60 gamma radiation. Radiat Res 1997; 147: 156-65.

43 Neumann MP, Limas C. Transitional cell carcinomas of the urinary bladder. Effects of preoperative irradiation on morphology. Cancer 1986;58:2758-63

44 Pazzaglia S, Chen XR, Aamodt $C B$, et al. In vitro radiation-induced neoplastic progression of low-grade uroepithelial tumors. Radiat Res 1994; 138:86-92.

45 Sheaff $M$, Baithum S. Pathological effects of ionizing radiation. Curr Diagn Pathol 1997;4:106.

46 Fajardo LF, Berthrong M. Radiation injury in surgical pathology. Am J Surg Pathol 1978;2:159-99.

47 Kanno J, Sakamoto A, Washizuka M, et al. Malignant mixed mesodermal tumor of bladder occurring after radiotherapy for cervical cancer: report of a case. J Urol 1985;133:854-6

48 Kamuhabwa AA, Cosserat-Gerardin I, Didelon J, et al. Biodistribution of hypericin in orthotopic transitional cell carcinoma bladder tumors. Implications for whole bladder wall photodynamic therapy. Int J Cancer 2002;897:253-60

49 Jichlinski P, Leisinger HJ. Photodynamic therapy in superficial bladder cancer: past, present and future. Urol Res 2001;29:396-405.

50 Muller M, Reich E, Steiner U, et al. Photodynamic effects of sulfonated aluminum chloroophthalocyanine in human urinary bladder carcinoma cells in vitro. Eur Urol 1997;32:339-43.

51 Kelly JF, Snell ME, Berenbaum MC. Photodynamic destruction of human bladder carcinoma. Br J Cancer 1975;31:237-44.

52 Kelly JF, Snell ME. Hematoporphyrin derivative: a possible aid in the diagnosis and therapy of carcinoma of the bladder. J Urol 1976;115:150-1.

53 Fanning CV, Staerkel GA, Sneige N, et al. Spindling artifact of urothelial cells in post-laser treatment urinary cytology. Diagn Cytopatho 1993;9:279-81.

54 Pisharodi LR, Bhan R. Spindling artifact of urothelial cells [letter]. Diagn Cytopathol 1995; 12:195

55 Prout GR, Jr, Lin CW, Benson R, Jr, et al. Photodynamic therapy with hematoporphyrin derivative in the treatment of superficial transitional-cell carcinoma of the bladder. N Engl J Med 1987;317:1251-5.

56 Smith JA. Surgical management of superficial bladder cancer. Semin Surg Oncol 1997;13:328-34.
57 Smith JA Jr. Laser treatment of bladder cancer. Semin Urol 1985;3:2-9.

58 Smith JA, Jr. Laser surgery for transitional cell carcinoma. Technique, advantages, and limitations. Urol Clin North Am 1992;19:473-83.

59 Das A, Gilling P, Fraundorfer M. Holmium laser resection of bladder tumors (HoLRBT). Tech Urol 1998;4:12-14.

60 Shanberg AM, Baghdassarian R, Tansey LA. Use of Nd:YAG laser in treatment of bladder cancer. Urology 1987;29:26-30.

61 Vicente J, Salvador J, Laguna P, et al. Histological evaluation of superficial bladder tumors treated by $\mathrm{Nd}$-YAG laser and transurethral resection. Eur Urol 1991:20:192-6.

62 Kardos R, Magasi P. Karsza A. Nd-YAG laser treatment of bladder tumors. Int Urol Nephrol 1994;26:317-22.

63 Keane TE, Petros JA, Velimirovich B, et al. Methoxypsoralen phototherapy of transitional cell carcinoma. Urology 1994;44:842-6.

64 Harimoto K, Sugimura K, Lee CR, et al. In vivo gene transfer methods in the bladder without viral vectors. Br J Urol 1998;81:870-4.

65 Akao T, Kakehi $Y$, Itoh N, et al. High prevalence of functiona inactivation by methylation modification of p161NK4A/CDKN2/MTS 1 gene in primary urothelial cancers. Jpn J Cancer Res 1997;88:1078-86.

66 Cote RJ, Dunn MD, Chatterjee SJ, et al. Elevated and absent pRb expression is associated with bladder cancer progression and has cooperative effect with p53. Cancer Res 1998;58:1090-4.

67 Kuball J, Wen SF, Leissner J, et al. Successful adenovirus mediated wild-type p53 gene transfer in patients with bladder cancer by intravesical vector instillation. J Clin Oncol 2002;15:957-65.

68 Stein JP, Ginsberg DA, Grossfeld GD, et al. Effect of p2 1WAF1/CIP1 expression on tumor progression in bladder. J Natl Cancer Inst 1998:90:1072-9.

69 Rigatti P, Lev A, Colombo R. Combined intravesical chemotherapy with mitomycin-C and local bladder microwave-induced hyperthermia as a preoperative therapy for superficial bladder tumors. A preliminary clinical study. Eur Urol 1991;20:204-10.

70 Shirikawa T, Sasaki R, Gardner TA, et al. Drug-resistant human bladder cancer cells are more sensitive to adenovirus-mediated wild-type p53 gene therapy compared to drug-sensitive cells. Int J Cancer 2001;94:282-9.

71 Ayala G, Kadmon D, Thomson T, et al. Cytopathic effects associated with HSV-tk gene therapy in human prostate cancer [abstract]. Mod Pathol 2000;13:532A

72 Ayala G, Kadmon D, Thomson T, et al. Local immunologic response in prostates of patients treated with suicide HSV-tk gene therapy [abstract]. Mod Pathol 2000;13:533A.

73 Wada Y, Gotoh A, Shirikawa T, et al. Gene therapy for bladder cancer using adenoviral vector. Mol Urol 2001;5:47-52.

74 Watanabe T, Shinohara N, Sazawa A, et al. Adenovirus mediated gene therapy for bladder cancer in an orthotopic model using a dominant negative $\mathrm{H}$-ras mutant. Int J Cancer 2001;92:712-17.

75 Jones EC, Clement PB, Young RH. Inflammatory pseudotumor of the urinary bladder: a clinicopathological, immunohistochemical, ultrastructural, and flow cytometric study of 13 cases. Am J Surg Pathol 1993; 17:264-74

76 Proppe KH, Scully RE, Rosai J. Postoperative spindle cell nodules of genitourinary tract resembling sarcomas. Report of 8 cases. Am J Surg Pathol 1984;8:101-8.

77 Helms CA, Clark RE. Post-herniorrhaphy granuloma simulating bladder neoplasm. Radiology 1977; 124:56-7.

78 Zilberman M, Laor E, Moriel E, et al. Paravesical granulomas masquerading as bladder neoplasms: late complications of inguinal hernia repair. J Urol 1990;143:489-91.

79 Pearl GS, Someren A. Suture granuloma simulating bladder neoplasm. Urology 1980;15:304-6.

80 Kandemir B, Aritas Y, Sade M. Malignant change in heterotopic bone formation following suprapubic cystolithotomy. J Urol 1984;132:558-9.

81 Spagnolo DV, Waring PM. Bladder granulomata after surgery. Am J Clin Pathol 1986;86:430-7.

82 Aragona F, DeCaro R, Parenti A, et al. Structural and ultrastructural changes in ileal neobladder mucosa: a 7-year follow-up. Br J Urol 1998; 181:55-61.

83 Filmer RB, Spencer JR. Malignancies in bladder augmentation and intestinal conduit. J Urol 1990;143:671-8.

84 Kochevar J. Adenomatoid tumor, goblet cell type, arising in a ureteroileal conduit: a case report. J Urol 1984;131:957-9.

85 Tancer ML. Vesicouterine fistula. A review. Obstet Gynecol Surv 1986;41:743-53.

86 Tomera K, Unni K, Utz D. Adenomatous polyp in ileal conduit. J Urol 1982;128:1025-6. 